\title{
Resenha: \\ Análise de texto: um olhar de semanticista
}

\author{
Sheila Elias de Oliveira ${ }^{1}$
}

Eduardo Guimarães ${ }^{2}$ tem se dedicado desde a década de 1980 à reflexão sobre o sentido na linguagem e nas línguas de um ponto de vista enunciativo, que coloca no centro desta reflexão a relação entre falante(s) e língua(s). Neste percurso, o texto tem sido incluído de modo fundamental na construção de uma abordagem teórico-metodológica que o autor vem chamando, nesta última década, de Semântica do Acontecimento ${ }^{1}$.

Seu primeiro livro autoral: Texto e argumentação: um estudo de conjunções no português ${ }^{2}$, de 1987, traz já no título a centralidade do texto na sua reflexão sobre um fato de linguagem que os Estudos da Enunciação, com Oswald Ducrot e J.-C. Anscombre, introduziram como questão para a Linguística: a argumentação.

Neste livro de 1987, a abordagem da argumentação proposta por Ducrot em parceria com Anscombre no domínio dos Estudos da Enunciação encontra, no diálogo com as teorias do sujeito e, mais especificamente com a Análise de Discurso, tal como ela já vinha sendo construída no Brasil por Eni Orlandi a partir da obra de Michel Pêcheux, um deslocamento fundamental: a argumentação passa a não ser tratada na relação entre enunciados, e sim na organização textual. O autor afirma, na época, que seu objetivo é “desenvolver um estudo semântico de construções da Língua Portuguesa observando o modo pelo qual estes aspectos constituem a organização textual” (Guimarães, 1987 [2007], p.11). Para tanto, postula a necessidade de construir um conceito de texto que se articule ao seu conjunto de preocupações (ibidem, p. 12), isto é, que inclua os modos de representação do sujeito da enunciação na descrição da organização textual e que traga para a explicação do funcionamento desta representação uma concepção de sujeito e de subjetividade.

O diálogo com a Análise de Discurso é, neste ponto, decisivo e sustenta a concepção de linguagem, em sua relação constitutiva com a subjetividade, posta em funcionamento na reflexão.

O texto, como "unidade empírica, com começo, e fim" é pensado "no processo discursivo", como "atravessado por várias posições do sujeito, sendo, também, uma dispersão de discursos" (ibidem, p.13). E se a "unidade de construção do discurso é o enunciado", este (o enunciado) deve ser "referido ao texto para poder ser apreendido no processo de construção do discurso (Orlandi e Guimarães, 1986³)" (Guimarães, 1987 [2007], p.13).

1 Professora da Universidade de Campinas - UNICAMP

2 GUIMARÃES, Eduardo. Análise de texto: procedimentos, análises, ensino. Campinas: RG Editora, 2011, $160 \mathrm{pp}$. 
Em Texto e argumentação (1987), a construção do conceito de texto serve à produção de uma descrição de um conjunto de conjunções do português; descrição esta que, ao tomar as conjunções como operadores de argumentação no texto, e não simplesmente como elementos de ligação entre orações, questiona a abordagem típica das gramáticas normativas, que então pautavam o ensino de língua nas escolas.

A sustentação em uma posição teórica sobre a linguagem, que olha a forma gramatical (a conjunção) em sua relação com a organização textual, levando em conta o modo como os segmentos articulados por conjunções se organizam em relação à enunciação, fortalece, naquele momento, a pertinência da ciência linguística, em particular aquela construída de uma perspectiva não imanente, para a compreensão dos fatos linguísticos, como fatos a serem explicados a partir da relação entre língua e linguagem. Fortalece, ainda, a pertinência do trabalho sobre o texto sustentado nesta ciência.

Em Análise de Texto, o objeto da reflexão é a interpretação de textos. O objetivo é, segundo o autor, "analisar textos. É procurar uma compreensão sobre como funciona e produz sentidos esta unidade complexa de significação que nos interroga sempre por caminhos, os mais inesperados" (Guimarães, 2011, p.13). E isto é feito a partir da posição de semanticista da enunciação, e tomando o texto como unidade de significação, mas sem esquecer que analisar textos e fazer descrições semânticas, ou construir uma semântica, são práticas que não se equivalem, já que o texto não é a unidade de análise de uma semântica linguística. Esta distinção confere especificidade ao trabalho de análise de texto, porque, de um lado, ela reconhece que há um deslocamento na prática do semanticista sobre o seu objeto habitual, e, de outro, ela precisa a perspectiva sobre a linguagem a partir da qual o texto será analisado: a de um semanticista da enunciação filiado ao materialismo histórico.

Desta posição, o autor segue os seguintes passos: na parte I, Fundamentos, ele apresenta a conceituação de texto, a caracterização do seu funcionamento e modo de constituição do sentido, e ainda a construção de um procedimento de análise; nas partes II e III, respectivamente, Análises: em torno da história do Brasil e Análises: outros textos não tão distantes, ele apresenta análises de textos; na parte IV, O texto na escola, reflete sobre o percurso realizado e sobre o ensino da interpretação de textos.

Em Fundamentos, o texto é conceituado como "unidade de sentido que integra enunciados no acontecimento da enunciação" (Guimarães, 2011, p.19). Se comparamos esta definição com a de 1987, apresentada acima, percebemos o deslocamento de uma unidade pensada como processo discursivo para uma unidade pensada em relação ao acontecimento enunciativo.

Se o processo discursivo é considerado como fundamento, e o reecontramos na retomada de conceitos como o de autor e o de recorte, presentes em 1987, há um olhar descritivo voltado para elementos enunciativos, pela retomada de conceitos e categorias descritivas como os de relação integrativa, enunciado, espaço de enunciação, cena enunciativa, articulação, reescrituração, introduzidos em outros textos do autor. Abrem-se então novas possibilidades de atravessamento da superfície textual e amplia-se o espaço de perguntas sobre a relação entre enunciação e discursividade.

No estabelecimento do procedimento de análise, o autor define o que ele entenderá por analisar: "interpretar os sentidos produzidos pelos textos, os sentidos que podemos reconhecer em um certo texto particular" (Guimarães, 2011, p.31). A interpretação passa a ser o foco da discussão e Guimarães especifica que ela se faz a partir de um lugar de leitor, tal como o de semanticista, que ele assume como o seu. Teoricamente, esta especificação se sustenta na explicitação da disparidade entre o lugar de Locutor e o de autor, e entre 
o lugar social de Locutor e o de leitor, o que leva à compreensão de que o lugar de leitor constitui um lugar de autoria, e de que como não se lê do lugar correlato ao de Autor, é preciso "dispor de um procedimento que estabelece uma distância e ao mesmo tempo exige uma descrição do material analisado" (ibidem, p.36).

O procedimento de análise vai sendo construído a partir da discussão de autores da Linguística e da Literatura, como Halliday e Hasan, Rifaterrre, Spitzer, e tem esteio no conceito de recorte, apropriado da Análise de Discurso e agora recolocado pelo autor em relação à enunciação. $\mathrm{O}$ procedimento envolve um conjunto de passos gerais, mas que não implicam que toda análise parta necessariamente das mesmas categorias específicas. Em relação ao que temos visto recorrentemente em abordagens que se fundamentam na noção de gênero textual para analisar o texto, o olhar de Guimarães abre o texto à sua instabilidade, às suas contingências, e dá visibilidade ao trabalho de linguagem - de locutor, de autor, de leitor - como um trabalho simbólico dinâmico, complexo, e não sustentado em regras, mas sim produtor de regularidades e de irregularidades nos modos de dizer e de organizar o que é dito.

As análises se dividem em "textos em torno da história do Brasil” e "outros textos nem tão distantes". Os primeiros incluem o texto da Proclamação da República, um outdoor produzido na época do que ficou conhecido como "escândalo do mensalão" em Brasília, e o parecer sobre o nome da língua nacional produzido para a Constituição da República de 1946. Os últimos incluem uma notícia jornalística, uma oração e um poema. Alguns deles retomam análises anteriores e as refazem a partir de certas categorias; outros são apresentados pela primeira vez. Juntos, eles dão visibilidade a uma dupla possibilidade: as análises podem responder a questões sobre cada texto individualmente, mas elas também podem produzir uma reflexão mais ampla sobre um tema em comum, como a história do Brasil, a política brasileira, as instituições brasileiras. Ou seja, analisar textos é um modo de produzir uma reflexão - mais ou menos extensa, mais ou menos geral - sobre as coisas.

Vou destacar do conjunto de análises a última apresentada, a do poema de Manuel Bandeira, Última Canção do Beco - uma pena que o poema não seja apresentado na íntegra, o que fica como sugestão para a próxima edição. Os recortes analisados por Guimarães são: as reescriturações (retomadas) da palavra "Beco"; a constituição da cena enunciativa (relação entre as figuras da enunciação e as formas linguísticas); a designação de "Beco" (sua significação no texto do poema); e aspectos formais da construção dos versos e estrofes. Este poema, que faz parte de uma série sobre o Beco, é analisado a partir da construção de uma orientação argumentativa - categoria não frequentemente mobilizada na análise de textos literários, e ainda menos de textos poéticos.

Guimarães mostra como o poema constrói enunciativamente o beco de que o eu-lírico/Locutor fala e o beco para que ele fala, e que esta divisão significa um jogo argumentativo entre o social e o íntimo e expõe o Beco às contradições que compõem o olhar do eu-lírico sobre ele (o Beco) neste texto. O movimento entre o íntimo e o social, entre o beco do poeta e o beco dos outros, significa também na construção formal das estrofes e das rimas, que produzem um lugar de irregularidade justamente onde se marca esta divisão. O que Guimarães realiza é uma análise semântica do texto, e não um exercício de crítica literária, mas ele não deixa de mobilizar a especificidade da construção do gênero literário canção, sem se prender à fixidez do gênero, o que permite ver os pontos de escape, e permite abrir o olhar sobre a relação entre forma - da língua, do texto - e sentido.

No geral, a riqueza dos textos apresentados e a minúcia de suas análises, sustentadas em um ponto de vista preciso sobre a linguagem e sobre o texto e em 


\section{Conexão Letras}

categorias mobilizadas com rigor, inscreve este livro de Guimarães no que me parece ser um lugar de respiro na reflexão atual sobre o texto, a qual tem em grande parte buscado a regra e a estabilidade, em detrimento do movimento simbólico de interpretação que sustenta seja a produção, seja a leitura de textos.

A qualidade da interpretação, do trabalho do sujeito sobre a linguagem é destacada ao final do livro em seu valor e em diferentes possibilidades no ensino, o que o autor faz, a meu ver, unindo dois aspectos essenciais: o primeiro, a necessidade da reflexão sustentada teórica e metodologicamente sobre a relação entre língua e linguagem, entre língua e texto, entre língua e subjetividade; o segundo, a tomada de posição mais ampla sobre o lugar do texto no ensino: nas palavras do autor, "analisar textos é um caminho para se pensar sobre as questões que nos interessam" (Guimarães, 2011, p.145). Eu diria ainda, para ampliar os interesses, modificá-los, confrontá-los e assim construir uma relação crítica consigo mesmo e com o mundo do qual se é parte. É o trabalho da escola na formação do sujeito, abrindo espaço para a apropriação de suas práticas enquanto falante. Não se trata, sem dúvida, de uma formulação nova. Mas se trata, sem dúvida, de uma formulação necessária, a se tomar fora da evidência dos sentidos.

\section{Notas}

1 Ver, entre outros, o livro homônimo Semântica do Acontecimento - GUIMARÃES, E. Semântica do Acontecimento. Campinas: Pontes, 2002, 96pp.

2 GUIMARÃES, E. Texto e argumentação: um estudo de conjunções no português. Campinas: Pontes, 1987, 200pp. Em 2007, foi feita uma reedição comemorativa dos vinte anos da primeira publicação desta obra, revista e ampliada, na qual o autor apresenta um posfácio em que avalia o tratamento dado por ele às conjunções do português na década de 1980 à luz dos desenvolvimentos de sua reflexão sobre a enunciação (GUIMARÃES, E. Texto e argumentação: um estudo de conjunções no português $-4^{\mathrm{a}}$ edição revista e ampliada. Campinas: Pontes, 1987, 216 pp.).

3 O autor faz referência ao texto escrito por ele em co-autoria com Eni Orlandi, na época no prelo e mais tarde publicado: ORLANDI, E.P. e GUIMARÃES, E. "Unidade e dispersão: uma questão do texto e do sujeito" in: Sujeito e texto. São Paulo: EDUC, Série cadernos PUC, n. 31, 1988. p. 17-35. 